\title{
Avaliação da transferência de imunidade passiva e de constituintes séricos de cordeiros Santa Inês nascidos de partos simples e gemelares no semiárido paraibano ${ }^{1}$
}

\author{
André R. Monteiro², Rodolfo T.S. Silva ${ }^{3}$, Patrício M. Souza ${ }^{4}$, \\ Fabiana Satake ${ }^{6}$, Karla C. Malta ${ }^{5}$ e Suedney L. Silva ${ }^{6 *}$
}

\begin{abstract}
Monteiro A.R., Silva R.T.S., Souza P.M., Satake F., Malta K.C. \& Silva S.L. 2018. [Evaluation of passive immunity transfer and serum constituents of Santa Ines lambs born of single and twin pregnancies in the semiarid region of Paraiba, Brazil.] Avaliação da transferência de imunidade passiva e de constituintes séricos de cordeiros Santa Inês nascidos de partos simples e gemelares no semiárido paraibano. Pesquisa Veterinária Brasileira 38(2):294-299. Departamento de Ciências Veterinárias, Centro de Ciências Agrárias, Universidade Federal da Paraíba, Campus II, Areia, PB 58397-000, Brazil. E-mail: suedney@cca.ufpb.br

This study is concerned with an evaluation of the influence of mode of birth on the transfer of passive immunity and some serum constituents to newborn lambs, naturally fed with colostrum, breed in the semiarid region of the State of Paraiba (Brazil) on an extensive system. Thirty-four clinically healthy Santa Ines lambs were employed, identified and weighted immediately after birth, and divided into two experimental groups of seventeen animals each. The PS group (nine males and eight females) included lambs born of single pregnancies and the PG group (six males and eleven females) comprised of lambs born of twin pregnancies. The colostrum intake occurred naturally and voluntarily at their mothers. Forty-eight hours after birth, $10 \mathrm{~mL}$ of blood were collected in siliconized tubes from each animal by puncture of the jugular vein, and maintained under vacuum. After centrifugation, aliquots of sera were separated and kept frozen at $-15^{\circ} \mathrm{C}$ until analyzed. For the comparative study of serum constituents, two experimental groups were formed, distributed in a completely randomized lineation, $2 \times 2$ factorial (type of birth and sex). The data were subjected to analysis of variance, whose means were compared by Tukey test at $5 \%$. The serum activities of AST and GGT, and the total protein serum, albumin, urea, creatinine, calcium, phosphorus and magnesium concentrations were determined by using sets of commercial reagents; the samples were read by an automatic spectrophotometer. The serum activities of AST, GGT and serum concentrations of total protein, albumin and globulins of the PS and PG lambs groups were not influenced by the type of pregnancy and sex. From the serum concentration of total protein, FTIP was found in the lambs of PG group, using the value of $5.0 \mathrm{~g} / \mathrm{dL}$ as the cutoff point. With the exception of calcium, serum concentrations of urea, creatinine, phosphorus and magnesium showed the same pattern. Although these constituents did not showed significant differences between groups and sex, higher values were observed in animals born of single pregnancies, suggesting that the absence of competition for the voluntary ingestion of colostrum may have been the determining factor. It can be concluded that lambs born twin deliveries and breed extensively in the semiarid region of the State of Paraiba failed to transfer passive immunity and showed significant reduction in serum levels of some biochemical constituents, indicating the need for human interference in these cases.
\end{abstract}

INDEX TERMS: Immunity transfer, sheep, newborns, colostrum, serum biochemistry, immunoglobulins.

\footnotetext{
${ }^{1}$ Recebido em 30 de agosto de 2016.

Aceito para publicação em 24 de agosto de 2017.

2 Programa de Pós-Graduação em Ciência Animal, Curso de Medicina Veterinária, Centro de Ciências Agrárias (CCA), Universidade Federal da Paraíba (UFPB), Campus II, Cidade Universitária, Areia, PB 58397-000, Brasil.

${ }^{3}$ Departamento de Ciências Veterinárias, CCA-UFPB, Campus II, Cidade Universitária, Areia, PB 58397-000.

${ }^{4}$ Centro de Ciências Biológicas e da Saúde, Universidade Federal de
}

Campina Grande (UFCG), Campina Grande, PB 58429-900, Brasil.

${ }^{5}$ Hospital Veterinário, CCA-UFPB, Campus II, Cidade Universitária, Areia, PB 58397-000.

${ }^{6}$ Departamento de Ciências Veterinárias, CCA-UFPB, Campus II, Cidade Universitária, Areia, PB 58397-000. *Autor para correspondência: suedney@cca.ufpb.br

${ }^{7}$ Labtest, Belo Horizonte, MG.

${ }^{8}$ MINDRAY, Analisador bioquímico BS-120. 
RESUMO.- 0 presente trabalho teve por objetivo avaliar a influência do tipo de parto sobre a transferência de imunidade passiva e de alguns constituintes séricos de cordeiros recém-nascidos, alimentados naturalmente com colostro materno, criados no semiárido paraibano em sistema extensivo. Foram utilizados 34 cordeiros clinicamente sadios, da raça Santa Inês, os quais foram identificados e pesados imediatamente após o nascimento e separados em dois grupos experimentais com 17 animais cada. 0 grupo PS (nove machos e oito fêmeas) formado por animais nascidos de partos simples e o grupo PG (seis machos e onze fêmeas) formado por cordeiros nascidos de partos gemelares. A ingestão de colostro se deu de forma natural e voluntária em suas respectivas mães. Foram coletados $10 \mathrm{~mL}$ de sangue de cada animal, mediante punção da veia jugular, em tubos siliconizados a vácuo, 48 horas após o nascimento. Após centrifugação, as alíquotas de soro foram separadas e permaneceram congeladas a $-15^{\circ} \mathrm{C}$ até o momento das análises. Para o estudo comparativo dos constituintes séricos, foram constituídos dois grupos experimentais distribuídos em um delineamento inteiramente casualizado, no esquema fatorial $2 \times 2$ (tipo de parto e sexo). Os dados obtidos foram submetidos à análise de variância, cujas médias foram comparadas pelo teste de Tukey a 5\%. Foram determinadas as atividades séricas das enzimas aspartato aminotransferase (AST) e gamaglutamiltransferase (GGT) e as concentrações séricas de proteína total, albumina, ureia, creatinina, cálcio, fósforo e magnésio, utilizando-se conjuntos de reagentes comerciais e as leituras das amostras em espectrofotồmetro automático. As atividades séricas de AST, GGT e as concentrações séricas de proteína total, albumina e globulinas dos cordeiros dos grupos PS e PG não foram influenciadas pelo tipo de gestação e sexo. A partir da concentração sérica de proteína total, verificou-se falha de transferência de imunidade passiva (FTIP) nos cordeiros do grupo PG, utilizando-se o valor 5,0g/dL como ponto de corte. Com exceção do cálcio, as concentrações séricas da ureia, creatinina, fósforo e magnésio apresentaram o mesmo padrão de comportamento. Embora esses constituintes não tenham apresentado diferença significativa entre os grupos estudados e o sexo, pôde-se observar valores mais elevados nos animais nascidos de partos simples, sugerindo que a ausência de concorrência pela ingestão voluntária de colostro materno pode ter sido o fator determinante. Pode-se concluir que cordeiros Santa Inês nascidos de partos gemelares e criados extensivamente no semiárido paraibano apresentam falha na transferência de imunidade passiva e alterações/diminuições marcantes nos teores séricos de alguns constituintes bioquímicos, suscitando a necessidade de interferência humana nestes casos.

TERMO DE INDEXAÇÃO: Imunidade passiva, cordeiros, ovinos, neonatos, colostro, bioquímica sérica, imunoglobulinas.

\section{INTRODUÇÃO}

O período neonatal é uma fase crítica para cordeiros recém-nascidos, que precisam se adaptar a vida extrauterina. A placenta sindesmocorial dos ruminantes os torna hipogamaglobulinêmicos (Fagliari et al. 1988, Borges et al. 2001), ou mesmo agamaglobulinêmicos (Arguello et al. 2004) ao nascimento. 0 intestino do ruminante recém-nascido não é seletivo e permite transferência de imunoglobulinas e outras macromoléculas circulantes apenas durante as primeiras 12 a 36 horas após o nascimento (Lilius \& Marnila 2001).
Este mecanismo de absorção dos componentes do colostro é favorecido ainda pela diminuição da atividade proteolítica no trato gastrointestinal de animais recém-nascidos (Guilloteau et al. 1983) e também de inibidores da tripsina presentes no colostro (Ramos et al. 2010). No entanto, a absorção de macromoléculas da mucosa intestinal para a circulação se torna diminuída a partir das 22 horas de vida (Yanaka et al. 2012a). Portanto, para ruminantes, a ingestão de colostro de qualidade, em volume suficiente e nas primeiras horas após o nascimento tem um papel fundamental na transferência de imunidade passiva e na taxa de sobrevivência de recém-nascidos (Castro et al. 2011).

Alguns outros fatores também podem levar à falha na transferência de imunidade passiva, como ocorre em casos de ovelhas primíparas ou mais velhas, de partos gemelares (Halliday 1976, Hunter et al. 1977, McGuire et al. 1983, Bekele et al. 1992, Christley et al. 2003), de parições durante o inverno (Gokçe et al. 2013), por desnutrição das ovelhas durante a gestação (Halliday 1978, Mellor \& Murray 1985, 1986), pelo nascimento de cordeiros prematuros ou com baixo peso ao nascimento (Gokçe et al. 2013). Portanto, é de extrema importância o reconhecimento desses fatores, pois pode fornecer bases e fundamentos para a adoção de medidas preventivas que evitem ou diminuam a incidência dessa condição em um rebanho.

Estudos foram realizados utilizando a determinação de proteínas séricas totais e seu fracionamento eletroforético como método de diagnóstico da transferência de imunidade passiva (TIP), ou utilizando a atividade sérica de gamaglutamiltransferase (GGT) como indicadora indireta da TIP em ovinos, devido a sua correlação positiva com a concentração sérica de IgG (Feitosa et al. 2001). Como a falha de transferência de imunidade passiva (FTIP) pode ser decorrente de diversos fatores, como idade da mãe, época de parição, condições nutricionais maternas, prematuridade neonatal e partos gemelares, o presente trabalho teve por objetivo avaliar o efeito do tipo de parto sobre a TIP e constituintes séricos de cordeiros recém-nascidos da raça Santa Inês, provenientes de partos simples e gemelares, mantidos em sistema extensivo de criação, 48 horas após o nascimento.

\section{MATERIAL E MÉTODOS}

Foram utilizados 34 cordeiros clinicamente sadios, da raça Santa Inês, criados em sistema extensivo, os quais foram identificados e pesados imediatamente após o nascimento e separados em dois grupos experimentais com 17 animais cada. 0 grupo PS, com nove machos e oito fêmeas, formado por animais nascidos de partos simples e o grupo $\mathrm{PG}$, com seis machos e onze fêmeas, formado por cordeiros nascidos de partos gemelares. Os cordeiros permaneceram integralmente com suas mães e a ingestão de colostro se deu de forma natural e voluntária.

Foram coletados $10 \mathrm{~mL}$ de sangue de cada animal, mediante punção da veia jugular, em tubos siliconizados a vácuo, 48 horas após o nascimento. Após centrifugação durante 10 minutos, as alíquotas de soro foram separadas e permaneceram congeladas a $-15^{\circ} \mathrm{C}$ até o momento das análises. Foram determinadas as atividades séricas das enzimas aspartato aminotransferase-AST (método cinético UV-IFCC) e GGT (método de Szasz modificado) e as concentrações séricas de proteína total (método do biureto), albumina (método 
verde de bromocresol), ureia (método cinético UV), creatinina (método Labtest), cálcio (método de CPC), fósforo (método Daly y Ertingshausen modificado) e magnésio (método Labtest), utilizando-se conjuntos de reagentes comerciais ${ }^{7}$. As leituras das amostras foram realizadas mediante espectrofotômetro automático ${ }^{8}$.

Para o estudo comparativo dos constituintes séricos foram formados dois grupos experimentais, distribuídos em um delineamento inteiramente casualizado, no esquema fatorial 2x2 (tipo de parto e sexo). Os dados obtidos foram submetidos à análise de variância, cujas medias foram comparadas pelo teste de Tukey a 5\%. Para a análise estatística foi utilizado o programa SISVAR 5.0.

\section{RESULTADOS}

Ao nascimento, o peso médio dos cordeiros provenientes de partos simples (PS) foi de 3,96 $\pm 0,52 \mathrm{~kg}$ e de $3,22 \pm 0,11 \mathrm{~kg}$ para aqueles nascidos de partos gemelares (PG).

As atividades séricas de AST e GGT e as concentrações séricas de proteínas totais, albumina e globulinas dos cordeiros dos grupos PS e PG não foram influenciadas pelo tipo de gestação e sexo (Quadro 1). Embora esses constituintes não tenham apresentado diferença significativa entre os grupos estudados e o sexo, pôde-se observar valores mais elevados nos animais nascidos de partos simples.

Com exceção do cálcio, as concentrações séricas da ureia, creatinina, fósforo e magnésio dos cordeiros dos grupos PS e PG não foram influenciadas pelo tipo de gestação e sexo (Quadro 2). Mesmo não tendo ocorrido diferença significativa nos constituintes séricos analisados, pôde-se observar valores mais elevados nos animais nascidos de partos simples, exceto da creatinina que apresentou valores iguais entre os dois grupos experimentais.

Quadro 1. Média e desvio-padrão das atividades séricas de AST (UI/L) e GGT (UI/L) e das concentrações séricas de proteína total (Pt - g/dL), albumina (Alb - g/dL) e globulinas (Glob - g/dL) de cordeiros nascidos de partos simples (PS) e gemelares (PG), 48 horas após o nascimento

\begin{tabular}{cccccc}
\hline \multirow{2}{*}{ Grupo } & \multicolumn{5}{c}{ Constituintes } \\
\cline { 2 - 6 } & AST & GGT & Pt & Alb & Glob \\
\hline PS & $55,0 \pm 12,9$ & $727,9 \pm 584,8$ & $5,5 \pm 1,3$ & $2,48 \pm 0,2$ & $3,0 \pm 1,3$ \\
PG & $50,7 \pm 14,5$ & $532,5 \pm 419,4$ & $4,9 \pm 1,1$ & $2,20 \pm 0,4$ & $2,7 \pm 1,0$
\end{tabular}

Quadro 2. Média e desvio-padrão das concentrações séricas de ureia $(\mathrm{mg} / \mathrm{dL})$, creatinina $(\mathrm{mg} / \mathrm{dL})$, cálcio $(\mathrm{mg} / \mathrm{dL})$, fósforo $(\mathrm{mg} / \mathrm{dL})$ e magnésio $(\mathrm{mg} / \mathrm{dL})$ de cordeiros nascidos de partos simples (PS) e gemelares (PG), 48 horas após o nascimento

\begin{tabular}{cllcrl}
\hline \multirow{2}{*}{ Grupo } & \multicolumn{5}{c}{ Constituintes } \\
\cline { 2 - 6 } & \multicolumn{1}{c}{ Ureia } & Creatinina & \multicolumn{1}{c}{ Cálcio } & Fósforo & Magnésio \\
\hline PS & $189,4 \pm 127,4$ & $1,8 \pm 1,2$ & $7,7 \pm 2,4^{\mathrm{b}}$ & $8,2 \pm 1,8$ & $1,5 \pm 0,5$ \\
PG & $128,3 \pm 73,8$ & $1,8 \pm 0,3$ & $6,1 \pm 1,4^{\mathrm{a}}$ & $7,7 \pm 1,6$ & $1,3 \pm 1,1$
\end{tabular}

Médias seguidas de letras minúsculas diferentes na mesma coluna diferem entre si pelo teste de Tukey $(\mathrm{p} \leq 0,05)$.

\section{DISCUSSÃO}

Cordeiros nascidos com valores menores que $3 \mathrm{~kg}$ são considerados com baixo peso corporal (Pugh 2004). Embora o baixo peso corporal ao nascimento não tenha sido observado no presente estudo, os cordeiros nascidos de parto simples tiveram maior peso em relação aos de partos gemelares, fato que pode determinar mais vitalidade e menor tempo entre $o$ nascimento e a primeira mamada efetiva de colostro.

Embora não ocorrendo diferença significativa dos constituintes séricos AST e GGT Pt, albumina e globulinas entre os grupos estudados, os maiores valores foram observados nos animais do grupo PS, sugerindo que a ausência de concorrência pela ingestão voluntária de colostro materno pode ter sido o fator determinante, e que essa concorrência deve ser considerada importante durante a implantação de manejo suplementar de colostro em cordeiros nascidos de partos gemelares.

A absorção intestinal de imunoglobulinas contidas no colostro é reduzida drasticamente com o passar do tempo, por isso, a ingestão de colostro deve ocorrer o mais brevemente possível após o parto, recomendando-se quantidades de colostro variando de 10 a $15 \%$ do peso corporal, para cordeiros e cabritos, nas primeiras 24 horas de vida, respectivamente (Morrical et al. 1995, Silva 2005), para assegurar a adequada transferência de imunidade passiva.

Neste estudo, a atividade sérica de AST encontra-se dentro dos valores considerados normais para ovinos, que varia de 60 a 280 UI/L (Kaneko et al. 1997), não ocorrendo influência das variáveis analisadas. Zanker et al. (2001), Gasparelli et al. (2008), Pekcan et al. (2013) determinaram que na espécie bovina o aumento pós-natal da atividade de AST não tem associação com o momento da primeira ingestão de colostro. Isso indica que o aumento da atividade dessa enzima seja decorrente da produção endógena e independente da ingestão do colostro.

A atividade sérica da GGT em ovinos sadios varia de 20 a 52 UI/L (Kaneko et al. 1997). Os valores obtidos foram mais elevados no grupo PS $(727,9 \pm 584,8 \mathrm{UI} / \mathrm{L})$, porém, menor do que os valores de $1.782,3 \pm 1.213,1$ e $1.616,0 \pm 1.096,4$ em ovinos mestiços únicos e gêmeos, respectivamente, 48 horas após o nascimento (Turquino et al. 2011). 0 aumento da atividade sérica da GGT no soro sanguíneo dos ovinos deste estudo foi semelhante àquela determinada em bovinos (Fagliari et al. 1996), (Fagliari et al. 1998), (Feitosa et al. 1999), (Feitosa et al. 2001), (Benesi et al. 2003) e em caprinos (Feitosa et al. 2006), (Silva et al. 2007) nos primeiros dias após a ingestão de colostro. Em bezerros com 24 a 48 horas de vida, considera-se como boa a excelente a TIP quando os valores séricos de GGT são maiores que $300 \mathrm{UI} / \mathrm{L}$ (Feitosa et al. 2010). Entretanto, o uso da atividade sérica de GGT como indicador indireto do sucesso da TIP é questionável, pois não se mostrou um método confiável em caprinos, por apresentar baixa correlação com a IgG (Silva 2005). Assim como também pode ser observado no Quadro 1, apesar da sua elevada atividade no grupo $\mathrm{PG}$, estes animais podem ser considerados com falha na TIP, usando como critério a concentração sérica de proteína total, considerando $5,0 \mathrm{~g} / \mathrm{dL}$ como ponto de corte, que é um indicador confiável do sucesso de TIP (Smith 2002).

Os valores séricos de proteína total, albumina e globulinas foram discretamente maiores nos animais do grupo PS, indicando provável relação com maior ingestão de colostro materno em relação aos cordeiros do grupo PG, sugerindo que a ausência de concorrência pela ingestão voluntária 
de colostro materno pode ter sido o fator determinante. A concentração sérica de proteína total considerada normal

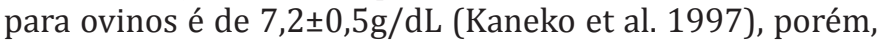
Campos et al. (2013) encontraram valores de 6,30 $\pm 1,04 \mathrm{~g} / \mathrm{dL}$ para ovinos da raça Santa Inês com 48 horas de vida. Resultados semelhantes $(6,03 \pm 1,1 \mathrm{~g} / \mathrm{dL})$ foram encontrados por Silva (2005), em caprinos com 48 horas após o nascimento, que ingeriram artificialmente entre 10 e $15 \%$ do seu peso corporal em colostro materno, nas primeiras 24 horas pós-parto. Valores ligeiramente maiores $(6,82 \pm 0,9 \mathrm{~g} / \mathrm{dL})$ também foram encontrados em cabritos com ingestão voluntária de colostro caprino à vontade, nas primeiras 48 horas de vida (Yanaka et al. 2012a).

Alguns autores verificaram valores estatisticamente mais elevados de Pt entre cordeiros nascidos de partos simples em relação aos nascidos de partos gemelares, tais como 8,32 $\pm 0,12$ e 7,93 $\pm 0,19 \mathrm{~g} / \mathrm{dL}$ (Bekele et al. 1992), 7,24 e 6,52g/dL

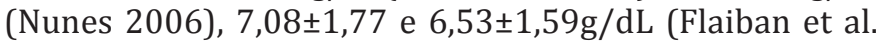
2009), 7,313 $\pm 1,112$ e 6,665 $\pm 1,164 \mathrm{~g} / \mathrm{dL}$ (Turquino et al. 2011). No presente estudo não houve diferença significativa para as concentrações séricas de Pt entre os dois grupos estudados e o grupo PS apresentou valor médio de Pt inferior ao observado na literatura em animais sob condições experimentais semelhantes, mesmo assim, podem ser considerados como sucesso na TIP, seguindo os critérios sugeridos por Smith (2002). Por outro lado, os valores encontrados no grupo PG indicam falha na TIP, uma vez que o valor de proteína total se encontra menor que 5,0 g/dL.

Os valores de albumina obtidos neste estudo foram ligeiramente inferiores em relação aos considerados normais para ovinos adultos $(2,7 \pm 0,2 \mathrm{~g} / \mathrm{dL})$ (Kaneko et al. 1997), bem como os valores de 2,88g/dL encontrados em ovinos Santa Inês com 48 horas de vida (Campos et al. 2013), de 2,78 $\pm 1,00 \mathrm{~g} / \mathrm{dL}$ em ovinos com 24-72 horas de vida (Silva et al. 2010) e de $3,276 \pm 0,669 \mathrm{~g} / \mathrm{dL}$ em ovinos machos com 24 horas de vida (Turquino et al. 2011). No entanto, foram semelhantes aos encontrados em caprinos da raça Boer $(2,48 \pm 0,25 \mathrm{~g} / \mathrm{dL})$ com 48 horas após o nascimento (Yanaka et al. 2012b). Como pode ser observado no Quadro 1, os valores de albumina foram ligeiramente maiores no grupo de cordeiros nascidos de partos simples em relação aos de partos gemelares, apesar de não terem diferença estatística. Sabendo-se que em recém-nascido o teor sérico de albumina é pouco variável, as diferenças nas concentrações proteicas ocorrem, quase que exclusivamente, devido à absorção de imunoglobulinas após a ingestão de colostro (Feitosa et al. 2001). Isso leva a crer que este fato tenha ocorrido devido à ingestão de maior volume de colostro no grupo de cordeiros nascidos de partos simples, provavelmente em função de maior oferta e ausência de competição pelo alimento.

Os teores séricos de globulinas nos dois grupos estudados foram inferiores aos encontrados por Turquino et al. (2011) em cordeiros machos e fêmeas após 24 horas de vida, $3,743 \pm 1,533$ e $4,042 \pm 1,393 \mathrm{~g} / \mathrm{dL}$, respectivamente, bem como os encontrados por Eloy et al. (2013) em caprinos da raça Moxotó nas primeiras 24 horas pós-natal. Do mesmo modo que a proteína total e a albumina, os valores séricos de globulinas nos cordeiros nascidos de parto simples foram mais elevados do que nos animais nascidos de partos gemelares. Essa diferença, provavelmente, foi decorrente da absorção de imunoglobulinas a partir da maior ingestão de colostro nos animais do referido grupo.

A concentração sérica de ureia foi maior nos dois grupos estudados em comparação aos valores de 8 a 20mg/dL considerados normais em ovinos adultos (Kaneko et al. 1997). Descartadas as possibilidades de interferências pré-analíticas e analíticas, possivelmente, esta elevação pode ter sido provocada pela ingestão de colostro com elevado teor de proteína, pois como relatado por alguns autores (Ferreira et al. 2011), ovelhas da raça Santa Inês produzem colostro com altos teores de proteína. Já a concentração sérica de creatinina está de acordo com os valores considerados normais para a espécie, que é de 1,2 a 1,9mg/dL (Kaneko et al. 1997). As concentrações séricas de creatinina são maiores no período pós-parto imediato, ou seja, antes da primeira mamada, entretanto, ocorre diminuição após a ingestão de colostro (Gasparelli et al. 2008, Yanaka et al. 2012b, Peckan et al. 2013). Esse fato pode ser atribuído a expansão do plasma sanguíneo após primeira mamada, devido à ação hidratante do colostro e início da filtração glomerular que determina a adequada eliminação deste componente pela urina nas primeiras horas de vida. As concentrações séricas de cálcio foram significativamente maiores nos animais do grupo PS. Os resultados obtidos encontram-se abaixo dos valores considerados normais $(12,16 \mathrm{mg} / \mathrm{dL})$ para ovinos adultos (Kaneko et al. 1997), para ovelhas Santa Inês no período pós-parto (10,93mg/dL) (Cardoso et al. 2011) e dos valores obtidos por Silva (2005) em caprinos 48 horas após o nascimento $(11,68 \mathrm{mg} / \mathrm{dL})$. No entanto, foram semelhantes $(7,674 \mathrm{mg} / \mathrm{dL})$ aos encontrados por Batista et al (2009) em ovinos com menos de 12 meses de vida.

A maior concentração sérica de cálcio encontrado no grupo PS, provavelmente ocorreu devido ao fato dos animais deste grupo terem ingerido maior quantidade de colostro devido à maior oferta e ausência de competição. Além disso, mesmo que o cálcio seja o mineral de maior abundancia na secreção mamária de ovelhas prenhes, não sofre aumento compensatório de suas concentrações na glândula mamária de ovelhas que geram um, dois ou três fetos simultaneamente (Souza et al. 2013).

A concentração sérica de fósforo foi sutilmente maior no grupo PS, indicando que os animais deste grupo provavelmente ingeriram um volume maior de colostro em relação ao grupo PG, já que este é o único alimento e, portanto, fonte disponível de fósforo a estes animais. Estes valores foram maiores que os encontrados em ovelhas Santa Inês no pós-parto (Cardoso et al. 2011) e menores que os encontrados em ovinos hígidos com menos de um ano de vida (Batista 2009).

Os teores séricos de magnésio $(\mathrm{Mg})$ nos animais dos dois grupos estudados foram mais baixos do que os encontrados para ovinos adultos (Kaneko et al. 1997), assim como em caprinos com 48 horas de vida (Silva 2005). 0 Mg é absorvido como um íon difundindo-se livremente. A eficiência absortiva deste mineral, que ocorre no intestino delgado e grosso até um mês de idade, é diminuída com o aumento da sua concentração dietética, quando a concentração plasmática de Mg está normal. Logo, os valores mais baixos encontrados neste estudo podem ter ocorrido devido à baixa aquisição de Mg através do colostro, quer seja pela sua baixa disponibilidade ou ingestão volumétrica insuficiente, pois se sabe que a homeostase da magnesemia se dá especialmente pelo seu aporte nutricional 
(Kaneko et al. 1997). Diante disso, o teor sérico deste íon, apesar de não ter variado estatisticamente entre os grupos estudados, foi ligeiramente maior no grupo PS o que pode ser atribuído também ao maior volume de colostro ingerido pelos animais deste grupo.

\section{CONCLUSÃO}

Pôde-se concluir que cordeiros Santa Inês nascidos de partos gemelares e criados extensivamente no semiárido paraibano, comparados a cordeiros nascidos de parto simples, apresentaram falha na transferência de imunidade passiva e alterações ou diminuições marcantes nos teores séricos de alguns constituintes bioquímicos, suscitando a necessidade de implantação de manejo suplementar de colostro em cordeiros nascidos de partos gemelares.

\section{REFERÊNCIAS}

Arguello A., Castro N., Zamorano M.J., Castroalonso A. \& Capote J. 2004. Passive transfer of immunity in kids goats fed refrigerated and frozen goat colostrum and commercial sheep colostrum. Small Rumin. Res. 54(3):237241. http://dx.doi.org/10.1016/j.smallrumres.2003.11.008.

Batista M.C.S., Castro R.S., Rego E.W., Carvalho F.A.A., Silva S.M.M.S., Carvalho C.C.D. \& Riet-Correa F. 2009. Hemograma, proteinograma, ionograma e dosagens bioquímicas e enzimáticas de ovinos acometidos por conidiobolomicose no Nordeste do Brasil. Pesq. Vet. Bras. 29(1):17-24. http://dx.doi.org/10.1590/S0100-736X2009000100002.

Bekele T., Otesile E.B. \& Kasali O.B. 1992. Influence of passively acquired colostral immunity on neonatal lamb mortality in Ethiopian highland sheep. Small Rumin. Res. 9(3):209-215. http://dx.doi.org/10.1016/09214488(92)90151-S.

Benesi F.J., Leal M.L.R., Lisbôa J.A.N., Coelho C.S. \& Mirandola R.M.S. 2003. Parâmetros bioquímicos para avaliação da função hepática em bezerras sadias, da raça holandesa, no primeiro mês de vida. Cienc. Rural 33(2):311317. http://dx.doi.org/10.1590/S0103-84782003000200020.

Borges A.S., Feitosa F.L.F., Benesi F.J., Birgel E.H. \& Mendes L.C.N. 2001. Influência da forma de administração e da quantidade fornecida de colostro sobre a concentração de proteína total e de suas frações eletroforéticas no soro sanguíneo de bezerros da raça Holandesa. Arq. Bras. Med. Vet. Zootec. 53(5):629-634. http://dx.doi.org/10.1590/S0102-09352001000500020.

Campos A.G.S., Afonso J.A.B., Mendonça C.L. \& Santos R.A. 2013. Administração de propilenoglicol, cobalto e vitamina b12 às ovelhas e seus reflexos sobre o perfil eletroforético das proteínas séricas nas suas crias. Cienc. Anim. Bras. 14(3):381-390. http://dx.doi.org/10.5216/cab.v14i3.6936.

Cardoso E.C., Oliveira D.R., Balaro M.F.A., Rodrigues L.F.S. \& Brandão F.Z. 2011. Índices produtivos e perfil metabólico de ovelhas Santa Inês no pós-parto no nordeste do Pará. Revta Bras. Cienc. Vet. (Heredia) 18(2/3):114-120.

Castro N., Capote J., Bruckmaier R.M. \& Arguello A. 2011. Management effects on colostrogenesis in small ruminants: a review. J. Appl. Anim. Res. 39(2):85-93. http://dx.doi.org/10.1080/09712119.2011.581625.

Christley R.M., Morgan K.L., Parkin T.D.H. \& French N.P. 2003. Factors related to the risk of neonatal mortality, birth-weight and serum immunoglobulin concentrations in lambs in the UK. Prev. Vet. Med. 57(4):209-226. http:// dx.doi.org/10.1016/S0167-5877(02)00235-0. PMid:12609466.

Eloy A.M.X., Andrade M.L.R., Pinheiro R.R., Da Silva N.M.M., Brito R.L.L., Santiago L.B., Lobo R.N.B. \& Furtado J.R. 2013. Estudo da dinâmica da absorção protéica do colostro em crias Moxotó e Saanen no Ceará. Rev. Bras. Med. Vet. 35(4):351-357.

Fagliari J.J., Oliveira E.C. \& Pegorer M.F. 1996. Relação entre o nível sérico de gamaglobulinas e as atividades de gamaglutamiltransferase, fosfatase alcalina e aspartato-aminotransferase de bezerros recém-nascidos. Arq. Bras. Med. Vet. Zootec. 48(2):105-112.
Fagliari J.J., Passipieri M., Curi P.R. \& Lucas A. 1988. Valores padrões das proteínas séricas de bovinos da raça Guzerá. II. Proteinograma sérico de bezerros recém-nascidos. Ars Vet. 4(2):225-232.

Fagliari J.J., Santana A.E., Lucas F.A., Campos Filho E. \& Curi P.R. 1998. Constituintes sanguíneos de bovinos recém-nascidos das raças Nelore (Bos indicus) e Holandesa (Bos taurus) e de Bubalinos (Bubalus bubalis) da raça Murrah. Arq. Bras. Med. Vet. Zootec. 50(3):253-262.

Feitosa F.L.F., Birgel E.H., Mendes L.C.N. \& Perri S.H.V. 1999. Relação entre a concentração de imunoglobulinas colostrais e a transferência de imunidade passiva para bezerros da raça Holandesa após ingestão voluntária de colostro. Ciênc. Vet. Tróp. 2(3):160-168.

Feitosa F.L.F., Birgel E.H., Mirandola R.M.S. \& Perri S.H.V. 2001. Diagnóstico de falha de transferência de imunidade passiva em bezerros através da determinação de proteína total e de suas frações eletroforéticas, imunoglobulinas $\mathrm{G}$ e $\mathrm{M}$ e da atividade da gamaglutamiltransferase no soro sanguíneo. Cienc. Rural 31(2):251-255. http://dx.doi.org/10.1590/ S0103-84782001000200010.

Feitosa F.L.F., Camargo D.G., Yanaka R., Mendes L.C.N., Peiró J.R., Bovino F., Lisboa J.A.N., Perri S.H.V. \& Gasparelli E.R.F. 2010. Índices de falha de transferência de imunidade passiva (FTIP) em bezerros holandeses e nelores, às 24 e 48 horas de vida: valores de proteína total, de gamaglobulina, de imunoglobulina $\mathrm{G}$ e da atividade sérica de gamaglutamiltransferase, para o diagnóstico de FTIP. Pesq. Vet. Bras. 30(8):696-704. http://dx.doi. org/10.1590/S0100-736X2010000800015.

Feitosa F.L.F., Mendes L.C.N., Peiró J.R., Ciarlini P.C., Marques F.J., Takada L. \& Perri S.H.V. 2006. Comparação do proteinograma e da atividade da gamaglutamiltransferase no soro sangüíneo de bezerros e de cabritos após ingestão de colostro. Ars Vet. 22(1):16-21.

Ferreira M.I.C., Borges I., Macedo Junior G.L., Rodriguez N.M., Penna C.F.A.M., Souza M.R., Gomes M.G.T., Souza F.A. \& Cavalcanti L.F. 2011. Produção e composição do leite de ovelhas Santa Inês e mestiças Lacaune e Santa Inês e desenvolvimento de seus cordeiros. Arq. Bras. Med. Vet. Zootec. 63(2):530-533. http://dx.doi.org/10.1590/S0102-09352011000200040.

Flaiban K.K.M.C., Balarin M.R.S.B., Ribeiro E.L.A., Castro F.A.B., Mori R.M. \& Lisboa J.A.N. 2009. Transferência de imunidade passiva em cordeiros cujas mães receberam dietas com diferentes níveis de energia ou proteína no terço final da gestação. Cienc. Anim. Bras. 1:181-185.

Gasparelli E.F., Camargo D.G., Yanaka R., Feres F.C., Vieira R.F.C., Perri S.H.V., Ciarlini P.C. \& Feitosa F.L.F. 2008. Influência do tipo de parto nos valores das enzimas hepáticas e ureia e creatinina de bezerros nelore oriundos de fertilização in vitro (FV) ao nascimento e às 24 horas de vida. Vet. Zootec. 15(2):360-369.

Gokçe E., Atakisi O., Kirmizigul A.H. \& Erdogan H.M. 2013. Risk factor sassociated with passive immunity, health, birth weight and growth performance in lambs: II. Effects of passive immunity and some risk factors on growth performance during the first 12 weeks of life. Kafkas Univ. Vet. Fak. Derg. 19:619-627.

Guilloteau P., Corring T., Garnot P., Martin P., Toullec R. \& Durand G. 1983. Effects of age and weaning on enzyme activities of abomasum and pancreas of the lamb. J. Dairy Sci. 66(11):2373-2385. http://dx.doi.org/10.3168/ jds.S0022-0302(83)82095-5. PMid:6197430.

Halliday R. 1976. Variations in immunoglobulin concentrations in Finnish x Dorset Horn lambs. Res. Vet. Sci. 21(3):331-334. PMid:1035975.

Halliday R. 1978. Immunity and health in young lambs. Vet. Rec. 103(22):489492. http://dx.doi.org/10.1136/vr.103.22.489. PMid:107648.

Hunter A.G., Reneau J.K. \& Williams J.B. 1977. Factors affecting IgG concentration in day-old lambs. J. Anim. Sci. 45(5):1146-1151. http://dx.doi.org/10.2527/ jas1977.4551146x. PMid:563861.

Kaneko J.J., Harvey J.W. \& Bruss M.L. 1997. Clinical Biochemistry of Domestic Animals. 5th ed. Academic Press, San Diego. 932p. 
Lilius E.M. \& Marnila P.2001. The role of colostral antibodies in prevention of microbial infections. Curr. Opin. Infect. Dis. 14(3):295-300. http://dx.doi. org/10.1097/00001432-200106000-00008. PMid:11964846.

McGuire T.C., Regnier J., Kellom T. \& Gates N. 1983. Failure in passive transfer of immunoglobulin G1 to lambs: measurement of immunoglobulin G1 in ewe colostrums. Am. J. Vet. Res. 44(6):1064-1067. PMid:6870009.

Mellor D.J. \& Murray L. 1985. Effects of maternal nutrition on udder development during late pregnancy and on colostrum production in Scottish Blackface ewes with twin lambs. Res. Vet. Sci. 39(2):230-234. PMid:4070789.

Mellor D.J. \& Murray L. 1986. Making the most of colostrum at lambing. Vet. Rec. 118(13):351-353. http://dx.doi.org/10.1136/vr.118.13.351. PMid:3705381.

Morrical D., Hartwing N.R. \& Youngs C. 1995. Colostrum and health of newborn lambs. Iowa State University, Ames. (Sheep Management Fact sheet 12)

Nunes A.B.V. 2006. Estudo da transmissão da imunidade passiva e da mortalidade em cordeiros mestiços de Santa Inês, na região Norte de Minas Gerais. Dissertação de Mestrado em Medicina Veterinária, Universidade Federal de Minas Gerais, Belo Horizonte, MG. 83p.

Pekcan M., Fidanci U.R., Yuceer B. \& Ozbeyaz C. 2013. Estimation of passive immunity in newborn calves with routine clinical chemistry measurements. Ankara Univet. Fak. Derg 60:85-88.

Pugh D.G. 2004. Clínica de Ovinos e Caprinos. Roca, São Paulo. 513p.

Ramos J.J., Loste A., Ferrer L.M., Fernandez A., Castro N., Ortin A., Verde M.T., Arguello A. \& Figueras L. 2010. Effect of addition of soybean trypsin inhibitor to colostrum on immunological status in goat kids. J. Anim. Physiol. Anim. Nutr. (Berl.) 94(1):93-98. http://dx.doi.org/10.1111/j.14390396.2008.00885.x. PMid:19364382.

Silva D.F.M., Costa J.N., Araújo A.L., Costa Neto A.O., Almeida M.Â.O. \& Carvalho V.S. 2010. Proteinograma sérico de cordeiros mestiços (Santa Inês $x$ Dorper) do nascimento até o desmame: efeito do desenvolvimento etário e do monitoramento da ingestão do colostro. Cienc. Anim. Bras. 11(4):794-805. http://dx.doi.org/10.5216/cab.v11i4.4848.
Silva S.L. 2005. Constituintes séricos e hematológicos de caprinos neonatos alimentados com colostros de cabras ou de vaca. Tese de Doutorado em Clínica Médica Veterinária, Faculdade de Ciências Agrárias e Veterinárias, Universidade Estadual Paulista, Campus de Jaboticabal, SP. 68p.

Silva S.L., Fagliari J.J., Barozo P.F.J., Cesco F.T.R.S. \& Jorge R.L.N. 2007. Avaliação da imunidade passiva em caprinos recém-nascidos alimentados com colostro de cabras ou colostro de vacas. Ars Vet. 23:81-88.

Smith B.P. 2002. Large Animal Internal Medicine. 3rd ed. Mosby, St Louis. 1735p.

Souza F.A., Borges I., Macedo Junior G.L., Silva V.B., Borges A.L.C.C. \& Saliba E.O.S. 2013. Composição corporal de cálcio e fósforo do útero gestante e da glândula mamária de ovelhas Santa Inês. Arq. Bras. Med. Vet. Zootec. 65(1):41-46. http://dx.doi.org/10.1590/S0102-09352013000100007.

Turquino C.F., Flaiban K.M.C. \& Lisbôa J.A.N. 2011. Transferência de imunidade passiva em cordeiros de manejos extensivamente em clima tropical. Pesq. Vet. Bras. 31(3):199-205. http://dx.doi.org/10.1590/ S0100-736X2011000300003.

Yanaka R., Camargo D.G., Bovino F., Santos W.A., Docusse M.R., Cavassano B.S. \& Feitosa F.L.F. 2012a. Período de absorção intestinal de macromoléculas em cabritos recém-nascidos após a ingestão de colostro bovino. Pesq. Vet. Bras. 32(8):794-802. http://dx.doi.org/10.1590/S0100736X2012000800020.

Yanaka R., Camargo D.G., Santos W.A., Cavassano B.S., Bovino F., Mendes L.C.N., Peiró J.R. \& Feitosa F.L.F. 2012b. Glicemia, proteinograma e perfil de alguns componentes bioquímicos séricos de cabritos da raça Bôer. Braz. J. Vet. Res. Anim. Sci. 49(1):30-38. http://dx.doi.org/10.11606/ issn.2318-3659.v49i1p30-38.

Zanker I.A., Hammon H.M. \& Blum J.W. 2001. Activities of gamaglutamyltransferase, alkaline phosphatase and aspartate amino transferase in colostrums, milk and blood plasma of calves fed first colostrums at 0-2, 6-7, 12-13 and 24-25h after birth. J Vet Med A Physiol Pathol Clin Med. 48(3):179-185. http://dx.doi.org/10.1046/j.14390442.2001.00338.x. PMid:11379391. 